\title{
Mobile Phones as Mediating Tools within Augmented Contexts for Development
}

\author{
John Cook, London Metropolitan University, UK
}

\begin{abstract}
This paper argues for the need to re-examine approaches to the design of, and research into, learning experiences that incorporate mobile phones in the learning context. Following an overview of 'mobile learning'the author's argument describes two initiatives: Firstly, Design Research is presented as an approach that tends to have interventionist characteristics, and is process-oriented and contributes to theory building. Secondly, describing Augmented Contexts for Development; these place context as a core construct that enables collaborative, location-based, mobile device-mediated problem-solving wherelearners generate their own 'temporal context for development', and a case study is used to reify this Vygotskian-oriented initiative. This paper revisits Design Research by making use of various questions, and concludes by briefly outlining intentions on how to move toward some preliminary generalized design principles and implications for broader theory.
\end{abstract}

Keywords: Attention and Perception in Learning, Augmented Contexts for Development, Design Research, Mobile Learning, Temporal Nature of Learning, Zone of Proximal Development

\section{INTRODUCTION}

The nature of learning is being augmented and accelerated by new digital tools and media, particularly by mobile devices and the networks and structures to which they connect people. 'Mobile learning' is an emerging, and rapidly expanding field of educational research and practice across schools, colleges and universities as well as in the work place (for example see: van't Hooft \& Swan, 2007; Sharples et al., 2008; Attwell et al., 2009; Pachler et al., 2010). It is also gaining increasing importance in what is frequently referred to as 'informal',

DOI: 10.4018/jmbl.2010070101 as opposed to 'formal', learning (see e.g., Cook et al., 2008) and it is starting to attract the interest and imagination of practitioners in all phases of education as well as of researchers. In view of the increasing portability and functional convergence of technologies, as well as the reduction in their cost, and the cost of services available for them, mobile devices have become more and more central to, and at the same time invisible in the life-worlds of users. Consequently, in this paper I argue for the need to re-examine approaches to the design of learning experiences that incorporate mobile phones in the learning context; such an undertaking seems particularly timely if we are to take full advantage of the affordances 
these devices provide in formal and informal contexts for learning.

Sharples etal. (2008, p. 5) conceive mobile learning as a "process of coming to know through conversations across multiple contexts amongst people and personal interactive technologies'. Pachler et al. (2010) note that although this definition is attractive, it may be too narrowly focussing on 'conversation', which foregrounds the link to people but underplays the linkages to systems and media structures (e.g., YouTube); this may be better expressed by the broader term 'communication'. Key characteristics of mobile devices include among other things increasing portability, functionality, multimedia convergence, ubiquity, personal ownership, social interactivity, context sensitivity, location awareness, connectivity and personalisation. In terms of context sensitivity, an important affordance of mobile technology is that of digital augmentation, whereby contextual data is added to objects to enable a deeper understanding of them and richer meaning making (I will return to this in the case study below). Furthermore, the multimodal affordances and characteristics of mobile devices are seen as important, particularly how images and soundrelated functionality impact on the input and output dimensions of interactions as well as the representation of information and knowledge.

An important question to consider with respect to mobile learning is this: what is there to commend mobile phone usage as a mediating tool for learning inside and outside the formal learning context? In answer to this question I have (elsewhere) drawn on the literature to delineate three phases of mobile learning (Pachler et al., 2010; Cook, 2009b): a focus on mobile devices, a focus on learning outside the classroom and a focus on the mobility of the learner. The beginnings of widespread experimentation with mobile devices for learning came in the mid 1990s. The first phase is characterised by a focus on what the mobile devices can be used to achieve in an educational context (PDAs, pen tablets, laptops or mobile phones) for formal education and training. This first phase, which in fact is still running in parallel with other phases, makes productive use of the affordances of mobile technologies such as e-books, classroom response systems, handheld computers in classrooms, data logging devices and reusable learning objects. A focus on learning outside the classroom is a characteristic of the second phase of mobile learning. The affordances in the second phase can include field trips, museum visits, professional updating, bite-sized learning and personal learning organisers. The third phase goes beyond mobile learning and is characterised by a focus on the mobility of the learner, the design or the appropriation of learning spaces and on informal learning and lifelong learning. There are three important affordances of the third phase: mixed reality learning, context sensitive learning and ambient learning (the latter includes augmented reality).

In this paper I argue for the need to reexamine approaches to the design of, and research into, learning experiences that incorporate mobile/cell phones in the learning context. I advance my argument by describing two initiatives. Firstly, below Design Research is presented as an approach that tends to have interventionist characteristics, is process oriented and contributes to theory building. Secondly, I go on to describe an educational problem that mobile learning tries to solve, plus propose a Design Research solution(Augmented Contexts for Development). The paper then revisits Design Research by making use of some key questions and concludes by briefly outlining how I intend to move towards some preliminary generalised design principles and implications for broader theory.

\section{DESIGN RESEARCH}

Design processes related to mobile devices inevitably involves designing for a 'match-box' sized, small interface. Issues include navigation over multiple platforms (i.e. different types of devices and operating systems), locating relevant information by providing usable navigation (through touch screens or buttons, etc), structuring of a learning task to suit the affordances of 
the mobile device, and evaluating that scenario (see Bradley et al., 2009 for a fuller discussion of all these issues). Furthermore, Bannan(2009) has pointed out that design and development processes - integrated with applied or empirical research cycles for the purposes of generating knowledge about teaching, learning or training, while simultaneously working toward producing a useful innovation or intervention-present a pronounced challenge.

One aim of Design Research (also called design-based research) is to identify and model technology-mediated, social learning and behaviours in order to design tools that support and promote the practices under investigation. For example, Cook (2002) has proposed a Design Research approach which revolves around evolutionary prototyping. What this means in simple terms is that we need to consider repeated cycles of: empirical work, theory/ model development and tool/artefact refinement. These particular aspects are typically conceived as overlapping activities and phases (rather than as sequenced 'steps'); it is thus an evolutionary Design Research approach to analyzing the role of theory/models, empirical work and technology in learning. Furthermore, the Design-Based Research Collective have proposed that: "The challenge of design-based research is in flexibly developing research trajectories that meet our dual goals of refining locally valuable innovations and developing more globally usable knowledge for the field" (Design-Based Research Collective, 2003,p. 7). Along similar lines, Plomp (2009) has recently noted that design research addresses complex problems in educational practice:

... educational design research is the systematic study of designing, developing and evaluating educational interventions (such as programs, teaching-learning strategies and materials, products and systems) as solutions for complex problems in educational practice, which also aims at advancing our knowledge about the characteristics of these interventions and the processes of designing and developing them. (p. 13)
Design Research thus tends to have interventionist characteristics is process-oriented and contributes to theory building (Plomp, 2009, p. 17). Indeed, Design Research is context-bound in nature, which means generalisations from this type of work tend not to be context-free. However, Design Researchers do strive for generalisable design principles whilst generalising to a broader theory (Plomp, 2009, p. 33). Consequently, we can conclude that the emerging Design Research approach (Cook, 2002; Bannan-Ritland, 2003; Design-Based Research Collective, 2003; Kelly, Baek, \& Lesh, 2008; Plomp \& Nieveen, 2009) provides a frame or lens through which we can examine the unique affordances of mobile learning.

In order to advance my argument (set out above) below I outline an educational problem plus proposed solution (Augmented Contexts for Development). I then proceed to specifically argue that our understanding of how to design for new mobile based, augmented contexts can benefit from a re-examination of Design Research; this re-examination will be achieved by exploring various key questions. The paper concludes by briefly outlining how I intend to move towards some preliminary generalised design principles and implications for broader theory.

\section{Augmented Contexts for Development}

In the introduction I argued that the context for learning in the $21^{\text {st }}$ Century is being augmented and accelerated by new digital tools and media, particularly by mobile devices and the networks and structures to which they connect people. An important question is this: do theories from the past provide explanatory power in today's context? In the 1930s Vygotsky proposed the Zone of Proximal Development (ZPD) as follows:

It is the distance between the actual developmental level as determined by independent problem solving and the level of potential problem solving as determined through problem solving under adult guidance or in collabo- 
ration with more capable peers. (Vygotsky, 1978/1930, p. 86)

The ZPD and the notion of a 'more capable peer' have become important notions for several design researchers. However, and this has not been built on in recent years, Vygotsky also pointed out that there is a temporal dimension to development that revolves around attention and perception:

Attention should be given first place among the major functions in the psychological structure underlying the use of tools ... the child is able to determine for herself the "centre of gravity" of her perceptual field; her behaviour is not regulated solely by the salience of individual elements with it ... In addition to reorganizing the visual-spatial field, the child, with the help of speech, creates a time field that is just as perceptible and real to him as the visual one. The speaking child has the ability to direct his attention in a dynamic way. He can view changes in his immediate situation from the point of view of activities, and he can act in the present from the viewpoint of the future (Vygotsky, 1978/1930, pp. 35-36).

The notions of time fields and the centre of gravity are important and any tools in an Augmented Context for Development should provide the visualisations that assist these underlying functions. Time fields in the Augmented Contexts for Development are created in context through tools, interactions and the internal reconstruction of these functions. A time field is a personal construct of an individual that is in particular based on the visual-spatial environment, speech, gestures and the current focus of attention (the latter will be influenced by historical factors that include the task and personal interest as well as socio-cultural factors). When all of these elements of the time field construct come together, we get what Vygotsky calls the centre of gravity of a time field. The centre of gravity becomes the focus of attention and is directed by a learner in a dynamic way as problem solving progresses and development and understanding takes place. The centre of gravity has a temporal dimension that guides activity across contexts, allowing the learner to dynamically direct attention so as to take into account the past (history), present activities and future planned desires and goals.

As already suggested above, society is currently witnessing a significant shift away from traditional forms of mass communication and editorial push towards user-generated content and augmented communication contexts. This has led me to conclude that Vygotsky's notion of a ZPD, which was developed in the context of $20^{\text {th }}$ Century Industrial Revolution, needs to be extended to what I am calling an Augmented Context for Development; below I use a case study in the Design Research context of a mobile phone based, location-aware field trip to explain this approach to learning design (i.e. a qualitative analysis is used to foreground process, explanatory perspectives, and the inner features of the situation; this is supported by questionnaire data). Specifically then, one educational problem that mobile learning tries to solve is the design of Augmented Contexts for Development (Cook, 2009a; Cook, 2009c); these place context as a core construct of the ZPD, enabling collaborative problem solving where learners generate their own 'context for development'. The demonstrator project for this concept was conducted as part of the EC CONTSENS project (www.ericsson.com/ contsens). In order to provide clarity it should be noted that (in the case described below) the researchers originally intend to promote improved visualization and co-construction within a ZPD. Following the running of the trial, the interactions between two students were analysed and mapped to the theory; the video analysis was thus used to look for evidence of, and provide an elaboration of, Augmented Contexts for Development.

The multimedia designer for the project (Carl Smith) made use of rich 3D visualizations and multimedia (see example in Figure 1) to augment the context for learning in such a way that would, we predicted (i.e., the development 
team: Smith et al., 2009), allow collaborating learners to interact: with each other, with the mobile phones and with the physical environment in order to generate their own context for development within a ZPD (Figure 2). Tasks were devised with an archaeology tutor from Sheffield University, UK, that gave students a framework within which to operate when on a field trip to a Cistercian abbey in Yorkshire, UK. One task, which is triggered when the mobile phone is in the correct GPS location on the site (at the abbey), stated: "Look at a movie (see Figure 1) of the reconstruction of the interior of the church including the NineAltars. Discuss the evolution of the structure of the abbey. Make a video blog of your discussion using the Nokia phone." The collaborating pairs had two phones, one with the $3 \mathrm{D} /$ multimedia visualizations running the location-based software MediaScape (www.mscapers.com/) and another mobile device for recording the video blog. Students were video recorded on the site by a researcher as they carried out the task and a questionnaire was used to gather feedback after the session.

An evaluation of the 10 MA Landscape Studies students involved in this small trial (Smith et al., 2009) obtained encouraging results. All the users made extremely positive comments about what they thought of the mobile learning course, describing it as "more fun" than expected, "I enjoyed it", "interesting", two said it was "very interesting, it was a "good idea", "good!", a "fantastic experience", and "very stimulating lots of good ideas". 80\% rated it as being useful for learning the subject. $60 \%$ thought the mobile device enhanced the learning experience. On the negative side, three found that having to look at the mobile devices was a distraction from engaging with the archaeology/site itself, and one would like more archaeological and historical explanation. However, $80 \%$ agreed that the mobile learning experience was fun, and 9 out of the 10 users would take another mobile learning course if

Figure 1. Screen shot of wire-frame movie reconstruction of Nine Alters

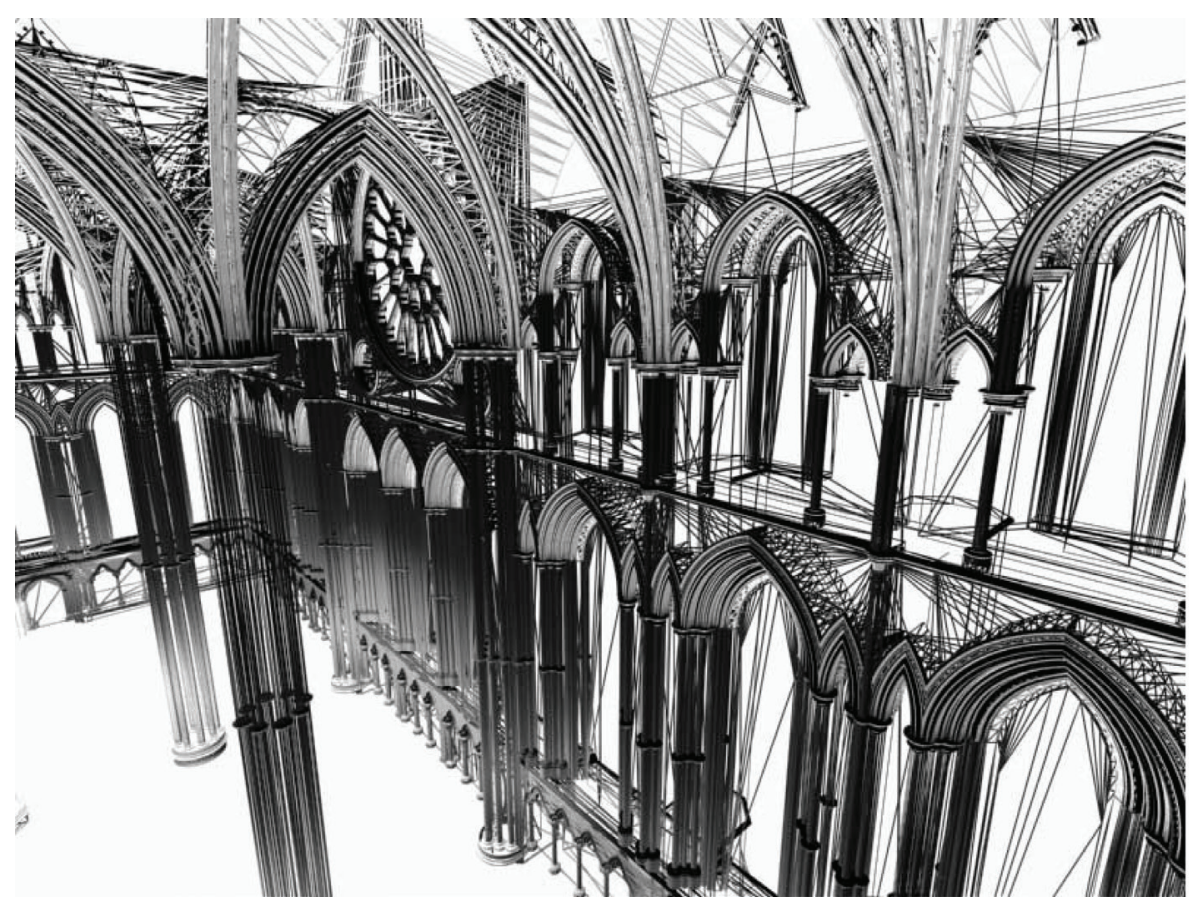

Copyright (C) 2010, IGI Global. Copying or distributing in print or electronic forms without written permission of IGI Global is prohibited. 
Figure 2. Students interacting at the Cistercian abbey (Fountains)

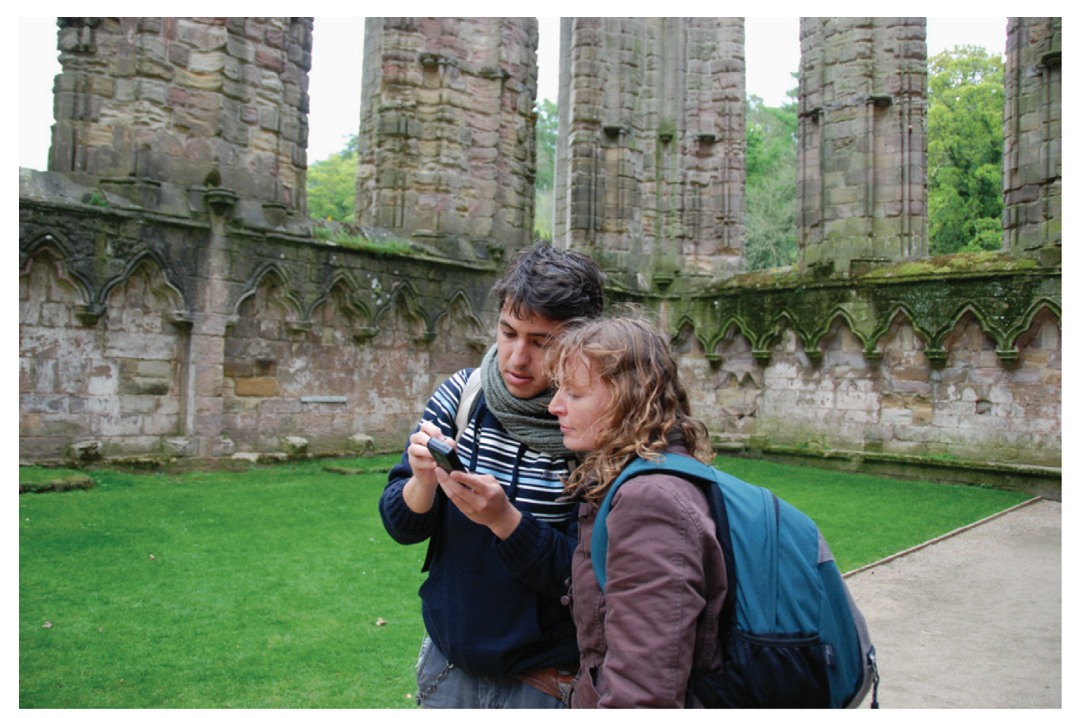

it was relevant to their learning needs and would recommend mobile learning as a method of study to others, which is a good indication that most of them had a positive experience. Indeed, one student commented: "The ability to be in a particular position but get a variety of views/ different visual perspective was a very useful opportunity. The whole thing also got everyone talking in a way I hadn't experienced on field trips to Fountains before."

The analysis in Table 1 (of video data captured on site) illustrates the emergence of a 'co-constructed area' linking the physical world (i.e., what is left of the Cistercian Abbey) and the virtual world that is visualised in $3 \mathrm{D}$ on the mobile devices (Figure 1); this 'area' is inhabited by a shared representation - or what Vygotsky calls a 'time field' (described above) - that is jointly developed and owned by the students.

Student 2 frequently uses the word 'see', indicating that the physical and digital representations interact and inform one another in real time. Also, the use of the word 'see' and the gestures in the video seem to indicate that the students are arriving at a co-constructed area/visualisation plus explanation that solves the problem of what changes have occurred to the abbey over time. There is a rapid interplay between external, tool-based and internal representations.

It is noteworthy that the Augmented Context for Development that we have created for the students appears to act as part of a substitute for what Vygotsky calls the 'more capable peer'. To summarise, the elements of an Augmented Contexts for Development (ACD) are:

(i) The physical environment (Cistercian abbey);

(ii) Pedagogical plan provided in advance by the tutor;

(iii) Tools for visualisation/augmentation oriented approach that create an umbrella 'Augmented Context for Development' for location based mobile devices (acts as part of the substitute for Vygotsky's 'more capable peer');

(iv) Learner co-constructed 'temporal context for development' (see below), created within a wider Augmented Context for Development through

(v) Collaborative learners' interpersonal interactions using tools (e.g. language, mobiles, etc) and signs; 


\title{
Table 1. Transcribed interaction of video clip captured on site
}

\author{
(Lots of pointing at screen and abbey; student 1 is female, student 2 is male). \\ Student 1: So those windows, up there isn't it, still? Is that right? So those have all changed since then. \\ Student 2: Yeah there was like another stage between this one and this one. \\ Student 1: High up. \\ Student 2: With three vaults. \\ Student 1: There's three on that side at the moment and three on that side. \\ Student 2. Yes \\ Student 1: So three have come down haven't they, along with the window. \\ Student 2: And from this? (points screen). That one is equal to that one, and actually we can not see that one \\ (points). We can see three vaults there ... \\ Student 1: There must have been ... \\ Student 2: That's the big one there. Can you see that? (points at screen) \\ Student 1: Do mean with the pillar? \\ Student 2: Yeah, you can see it's this way (?) but it's stopped there. \\ Student 1: That's right (makes gestures for a pillar and they both stare into the space where the missing pillar \\ should be).
}

(vi) These aforementioned elements (i-v) lead to intrapersonal (internal) representations of the above functions.

Within our emergent design (the ACD) the learners generate and embed their own 'temporal context for development' as they evolve their understanding of the architectural form under investigation. The notions of attention, perception and temporality seem key processes in the Augmented and Temporal Contexts for Development and worthy of further investigation. Specifically, the CONTSENS case study is used below to explore various key questions pertaining to the design of mobile learning environments and thus re-examine the way in which we conduct Design Research in this area.

\section{Discussion of Case Study Using Key Questions}

Vavoula et al. (2009) produced a useful collection of papers on research methods for mobile learning. Although the work presented tends to be oriented towards an educational research methods perspective, Design Research issues are represented in several chapters. However, it is fair to assert that Design Research work in the context of mobile learning is still in its early days. In this section I discuss the above case study using two key questions (adapted from Bannan, 2009) with a view to using the insights that the ensuing discussion provides in future participatory Design Research efforts. The questions are:

1. What does the shift in the use of mobile devices for informal, formal and workbased learning mean for the collection and analysis of data and what methods might we employ in a systematic, iterative and interventionist Design Research effort?

2. How do we employ the theoretical frame of the 'Augmented Contexts for Development' in a systematic process of identifying, generating and determining directions for design and research cycles? Specifically, are the notions of communication, 'more capable peer', perception, attention and temporality useful ways forward for Design Research into mobile learning?

Due to space limitations, I can only posit some preliminary answers to the above questions. That said, employing the lens of Augmented Contexts for Development has the potential to promote improved articulation of a Design Research approach by targeting specific aspects of the learner experience and learning context across analysis, design, development, implementation and evaluation phases. 
With respect to question 1, narrative and case-based approaches underpinned by grounded theory have already proved successful in earlier Design Research work investigating the relationship between mobile learning for on-campus learning and the learning that takes place more informally off campus (Cook et al., 2008; Pachler et al., 2009). These approaches could be used as methods to obtain a longitudinal perspective as we track the parameters of communication, more capable peer, attention, perception etc. across multiple contexts. It may be possible to use applied ethnographic methods as well as other techniques to capture and learn from issues surrounding Augmented and Temporal Contexts for Development. Priestnall et al. (2009) have already articulated off-site issues for Geography field trips. The techniques used in their study were: a pre-prepared acetate overlay of the visual scene; a custom-designed visitor guide running on a PDA; location-based software running on a GPS-enabled mobile phone (MediaScape); Google Earth on a tablet PC; and a head-mounted virtual reality display. One issue was that the mobile devices used in the trials gave poor screen visibility in the field; this is an emerging factor for Design Research in this area in that from a technology perspective, the techniques in use are still in their infancy and in some case the quality of screen visibility in bright daylight may restrict the usability of a system.

Regarding question 2, in the above case study, I captured and then analyzed an instantiation of an aspect of the situation of learning, learner-generated content and temporal contexts for development. This approach has the potential to inform both mobile learning design and research outcomes. The situated and temporal dimensions, of attention and perception, identified in the case study will require innovative data collection methods in follow-up work. Specifically, Mike Sharples has commented (Personal communication in closed Ning discussion forum related to Cook, 2009a, November, 2009) on the above Augmented Contexts for Development proposal as is stands as follows: "I like the core concept of "Augmented Context for Development" (ACD) in raising context as a core construct of the ZPD. One issue in relation to "time field" is whether, and how, the context can be maintained such that it persists as a scaffold. A concern would be that the ACD is both so salient and so ephemeral that it captures immediate attention (perhaps to the detriment of other more relevant visual cues and representations) but does not support a continuity of learning over time and across contexts." This is an insightful comment. Indeed, as the above evaluation showed, three study participants found that having to look at the mobile devices was a distraction from engaging with the archaeology site itself. This issue will need further consideration in the future. However, in a sense we are hitting the granularity problem; my aim in the above analysis was to provide a qualitative analysis from a process and explanatory perspective. I was therefore looking at the inner features of the situation. The temporal issues involved in terms of perception and attention took place on a minute by minute basis but have wider implications for communications across contexts. In fact, Vygotsky made a clear distinction between development and learning, with the latter acting as a wider frame that pulls development along. Having now related this temporal 'insight' back to theory (i.e., to Vygotsky's and time fields discussed above), a longitudinal study is called for that looks at these issues across contexts. In further studies our research team will use a head mounted camera in order to capture 'first person' video data of learners 'in and across contexts'. Indeed, Beddall-Hill (2009) has already made use of such an approach. Beddall-Hill (2009) describes a study where initial research focused on intensive observation of two field teaching settings supported by video, audio, photography, field notes and focus groups. Data was collected during two separate postgraduate geographic information systems field trips. Non-participatory observation was decoupled from the assessment process so that students could freely discuss their experiences, difficulties and learning processes while in the field and during a post assessment focus group. 
During one of the field trips, Beddall-Hill reports that she "was able to use a head mounted camera to collect multimedia data of the students using the devices. This has proven to be an excellent tool with good quality sound of the students' discussions and a visual picture of the environment and the interactions with and around the device". Indeed, we can envisage a situation in the future where eye-tracking apparatus could be used to observe attention. A research approach as described, with longer cycles and across multiple contexts, would only improve the implementation and articulation of Design Research methods. However, it should be noted that ethical considerations abound in relation to tracking learner movements and activity on tasks. Head-mounted data capture is also an invasive technique and until it becomes the norm it may 'skew' data collected (i.e., producing user behaviour that is not 'normal'). Finally, how all this mass of qualitative data can be used in the design and research process in a meaningful way is still also an issue.

\section{CONCLUSION}

In this paper I have argued for the need to reexamine approaches to the design of learning experiences that incorporate mobile phones in the learning context. I explored and mapped out design and research processes for mobile phonebased Augmented Contexts for Development, and applied these insights towards planned Design Research efforts. It is true that some technologies and techniques related to mobile learning are in their infancy; however, learning from the failure of a particular implementation is important information as well - failure in usability, failure in operationalisation of construct, failure in promoting attention, perception, learning, etc. This can provide an important Design Research outcome as well and suggesting revisions to the learning/teaching system. As was pointed out above, the researchers originally intend to promote improved visualization and co-construction within a ZPD. Following the running of the CONTSENS trial, the interac- tions between two students were analysed and mapped to the theory; the video analysis was thus used to look for evidence of and elaborations of Augmented Contexts for Development. Essentially, the success of the exploratory analysis has moved the focus of the Design Research forward from the originally intended learning experience/identified constructs; i.e. the focus has moved on to investigating change within a particular context and across cycles of Design Research.

Some additional connections between this exploratory work and future design research can now be generated. Specifically, the paper concludes by briefly outlining the questions that will help myself and the Learning Technology Research Institute team, in future work, move towards some preliminary generalised design principles and implications for broader theory.

- What similar work has been carried out on attention, perception and temporality in learning? How can the positive and deficit aspects of attention be designed for in the mobile learning environment?

- Has the Augmented Context for Development that we (the design and research team) have created for the students acted as part of a substitute for what Vygotsky calls the 'more capable peer'?

- During their continuing learning activities, what will the learning trail left behind by learners tell us as they move from one learning context to the next? How does this relate to lower granularity developmental events (the time fields)? How can we improve our understanding of how elements of context can be maintained over time, so as to scaffold a perceived continuity of learning?

- Can case studies like the above Cistercian abbey case be used to generate parameters that can in turn be used to build Augmented Context for Development in other areas?

- How does the work described in this paper relate to Vygotsky's (1978/1930) notion of the functions of intention and symbolic representations of purposeful action? 
- What are the implications of the above conceptually driven notion of Augmented Contexts for Development for the emerging field of mobile augmented reality (which tends to be driven by commercial developments)?

The above questions form the basis of a mobile learning Design Research agenda; the answer to any of these questions would represent a useful contribution to knowledge in the field of mobile learning. The questions will inevitably lead to changes in the designed learning experience, instantiated theory of Augmented Contexts for Development as well as future technology design based on this exploratory study.

One question above asks what viable evidence will comprise learning trails within mobile learning experiences? Will this include observational video, self-report, log files, click streams, eye tracking, directed attention via head-mounted displays etc? Also, how do we analyse the mass of data? It seems analysing these multiple, rich data streams require new ways of integrating evidence and investigating change that demonstrates learning (beyond the traditional inferential statistical analysis of answers on a test). Identifying and targeting phenomena such as attention and perception processes related to theory seems a good beginning in order to attempt to track related, intended behavioural outcomes and consequences across time and context. This is no easy task even in a single context over a short period of time, let alone over multiple time periods and contexts of use.

Another question posed above also raises issues surrounding the selected granularity or episodic views of interaction among the participants, tools and context; this seems an important consideration in this type of research. Identifying the appropriate unit of analysis related to the operationalised theoretical construct and then finding ways to trace the instantiation through demonstrated changes in behaviour or knowledge is paramount. However, as Kelly (2004) argues, researchers who implement Design Research continue to face this challenge (as Design Research incorporates dynamic and moving target type of phenomenon) as we collectively work toward establishing an "argumentative grammar" or logic for Design Research.

Furthermore, understanding that most hardware and software features are driven by commercial rather than educational priorities is also an important point raised above. The potential for design or redesign of mobile hardware and software features may be non-existent or severely constrained in most settings. The design researcher at that point is limited to the design and potential re-design of the instructional/ learning experience implementing existing technology features but attempting to capitalise on their affordances.

Clearly, sustained targets of investigation across multiple and iterative cycles of design, enactment and impact of the mobile intervention in and across the context(s) of use is important to consider and often difficult for researchers to consistently and systematically incorporate in these complex learning environments. Determining the identified and operationalised constructs that directly relate to the pedagogical/ theoretical approach, technological tools, and specific affordances of those tools implemented in context a priori in a Design Research study, as well as clearly identifying their impact for teaching and learning, is the core challenge in Design Research. Consequently, and in summary, it is claimed that this paper presents important questions and insights for consideration by the field at the intersection of mobile learning and Design Research.

\section{ACKNOWLEDGMENT}

The anonymous reviews helped improve this paper and many of the salient comments that expand on issues that I raise have been incorporated in this final version. Carl Smith and Claire Bradshaw are members of the LTRI team who developed and evaluated the CONTSENS work. CONTSENS was funded by EC Leonardo Lifelong Learning Programme. 


\section{REFERENCES}

Attwell, G., Cook, J., \& Ravenscroft, A. (2009, September 16-18). Appropriating Technologies for Contextual Knowledge: Mobile Personal Learning Environments. In D. Miltiadis, D. Lytras, P. O. de Pablos, E. Damiani, D. Avison, A. Naeve, \& D. G. Horner (Eds.), Proceedings of Best Practices for the Knowledge Society. Knowledge, Learning, Development and Technology for All Second World Summit on the Knowledge Society (WSKS 2009), Chania, Greece. Berlin: Springer.

Bannan, B. (2009, December 3-4). Challenges for Integrative Design and Research in Mobile Learning. In Proceedings of the Workshop Technology-Enhanced Learning in the Context of Technological, Societal and Cultural Transformation. Alpine Rendez-Vous, within the framework of the STELLAR Network of Excellence, Garmisch-Partenkirchen, Germany.

Bannan-Ritland, B. (2003). The Role of Design in Research: The Integrative Learning Design Framework. Educational Researcher, 32(1), 21-24. doi:10.3102/0013189X032001021

Beddall-Hill, N. L. (2009, December 3-4). Learning in Mobile Settings. In Proceedings of the Workshop: Education in the Wild. Alpine Rendez-Vous, within the framework of the STELLAR Network of Excellence, Garmisch-Partenkirchen, Germany.

Bradley, C., Haynes, R., Cook, J., Boyle, T., \& Smith, C. (2009). Design and Development of Multimedia Learning Objects for Mobile Phones. In M. Ally (Ed.), Mobile Learning in Education and Training. Athabasca, Canada: Athabasca University Press. Retrieved from http://www.aupress.ca/books/120155/ ebook/08_Mohamed_Ally_2009-Article8.pdf

Cook, J. (2002). The Role of Dialogue in ComputerBased Learning and Observing Learning: An Evolutionary Approach to Theory. Journal of Interactive Media in Education, 5, Retrieved from http://wwwjime.open.ac.uk/2002/5.

Cook, J. (2009a, December 3-4). Mobile Phones as Mediating Tools within Augmented Contexts for Development. In Proceedings of the Workshop: Education in the Wild. Alpine Rendez-Vous, within the framework of the STELLAR Network of Excellence, Garmisch-Partenkirchen, Germany.

Cook, J. (2009b, May 30-June 6). Phases of Mobile Learning. Invited lecture at Joint European Summer School on Technology Enhanced Learning 2009, Terchova, Slovakia. Retrieved from http://tinyurl. com/psejxu
Cook, J. (2009c, December 3-4). Literacy - Hindsight, Insight and Foresight. Paper presented at the Workshop on Technology-enhanced learning in the context of technological, societal and cultural transformations. Alpine Rendez-Vous, within the framework of the STELLAR Network of Excellence, Garmisch-Partenkirchen, Germany. Retrieved from http://bit.ly/8KqBmH

Cook, J., Pachler, N., \& Bradley, C. (2008). Bridging the Gap? Mobile Phones at the Interface between Informal and Formal Learning. Journal of the Research Center for Educational Technology. Retrieved from http://www.rcetj.org/index.php/rcetj/article/view/34

Design-Based Research Collective. (2003). Design-Based Research: An Emerging Paradigm for Educational Inquiry. Educational Researcher, 32(1), 5-8. Retrieved July 2005, from http://www. designbasedresearch.org/reppubs/DBRC2003.pdf

Kelly, A. E. (2004). Yes, but is it methodological? Journal of the Learning Sciences, 13(1), 115-128. doi:10.1207/s15327809j1s1301_6

Kelly,A.E., Lesh, R. A., \& Baek, J. Y.(Eds.). (2008). Handbook of Design Research Methods in Education Innovations in Science, Technology, Engineering, and Mathematics Learning and Teaching. New York: Lawrence Erlbaum Associates.

Pachler, N., Bachmair, B., \& Cook, J. (2010). Mobile Learning: Structures, Agency, Practices. New York: Springer.

Pachler, N., Cook, J., \& Bradley, C. (2009). "I don't really see it": Whither case-based approaches to understanding off-site and on-campus mobile learning? In Vavoula, G. (Ed.), $N$.

Pachler, \& A. Kukulska-Hulme (Eds.), Researching mobile learning: frameworks, tools and research designs (pp. 77-95). Oxford, UK: Peter Lang Publishing.

Plomp, T. (2009). Educational Design Research: An Introduction . In Plomp, T., \& Nieveen, N. (Eds.), An Introduction to Educational Design Research. Enschede, The Netherlands: SLO Netherlands Institute for Curriculum Development.

Plomp, T., \& Nieveen, N. (2009). Introduction to Educational Design Research. Enschede, The Netherlands: SLO Netherlands Institute for Curriculum Development.

Priestnall, G., Brown, E., Sharples, M., \& Polmear, G. (2009, October 28-30).AStudent-Led Comparison of Techniques for Augmenting the Field Experience. In Proceedings of Mlearn 2009, Orlando, FL. 
Sharples, M., Milrad, M., Arnedillo-Sánchez, I., \& Vavoula, G. (2008). Mobile Learning: Small devices, Big Issues. In N. Balacheff, S. Ludvigsen, T. de Jong, A. Lazonder, S. Barnes, \& L. Montandon (Eds.), Technology enhanced learning: Principles and products. Berlin: Springer. Retrieved January 2009, from http://www.lsri.nottingh $\backslash$ am.ac.uk/msh/ Papers/KAL_Legacy_Mobile_Learning.pdf

Smith, C., Bradley, C., \& Cook, J. (2009). Internal Report on the Evaluation of the Cistercian Abbey Project (CONTSENSLLL Project). London: London Metropolitan University. van't Hooft, M., \& Swan, K. (2007). Epilogue . In van't Hooft, M., \& Swan, K. (Eds.), Ubiquitous Computing in Education. Invisible technology, Visible Impact (pp. 349-351). Mahwah, NJ: Lawrence Erlbaum.

Vavoula, G., Pachler, N., \& Kukulska-Hulme, A. (Eds.). (2009). Research Methods in Mobile and Informal Learning. New York: Peter Lang Publishing Group.

Vygotsky, L. (1978). Mind in society. The development of higher psychological processes (Cole, M., Eds.). Cambridge, MA: Harvard University Press. (Original work published 1930)

John Cook is Professor of Technology Enhanced Learning at the Learning Technology Research Institute, London Metropolitan University and a member of the London Mobile Learning Group. John has published widely, having a specific interest in four related research areas: informal learning, mobile learning, appropriation and work-based learning. He has extensive project management experience, which includes AHRB, BECTA, HEFCE (CETL Manager 2005-2008) and EC work. John was Chair/President of the Association for Learning Technology (2004-06) and he is currently the Chair of ALT's Research Committee. John sits on various journal editorial boards and conducts Assessor and review work for the ESRC, EPSRC, EU, DfES and Science Foundation of Ireland. 